\title{
Hypothesis
}

\section{Trichloroethylene cranial neuropathy: is it really a toxic neuropathy or does it activate latent herpes virus?}

\author{
J B CAVANAGH, * P H BUXTON†
}

From St Edmund's College, Cambridge and The Toxicology Unit, MRC Laboratories, Carshalton, Surrey*; The Neuropathological Laboratory, $†$ Walton Hospital, Liverpool, UK

SUMMARY The mechanism of the cranial neuropathy associated with heavy exposure to trichloroethylene (or dichloroethylene) is unknown. In severe cases there is destructive spread of the neuropathic process from the Vth cranial nerve nuclei up and down the brain stem in a manner that is difficult to explain on accepted neurotoxicological principles. However, there is a close association reported of this form of trigeminal neuropathy with reactivation of orofacial herpes simplex that suggests the possibility that the chemical, which readily gains entrance into the nervous system, may be responsible for reactivating the latent virus. This novel hypothesis is discussed in the light of current understanding of latency in herpes simplex infection in nervous tissue.

The neuropathy that follows heavy exposure to trichloroethylene ("Trilene": TCE) (or to dichloroacetylene) is toxicologically unique in producing a pattern of nerve degeneration not found with any other solvent or chemical. The clinical condition poses a number of puzzling neuropathological questions that have never been satisfactorily answered, because the clinical condition always commences in the Vth cranial nerve sensory area with subjective sensory disturbances often being the only abnormality, and usually, though not always, all three components of the nerve are involved. In more severely affected subjects, objective trigeminal sensory abnormalities may be detected a little while later and with signs of damage, that may or may not be transient, to the Vth motor nerve fibres as well as to other cranial nerves. Thus, diplopia is commonly reported, while facial palsy, dysarthria, dysphagia and dysphonia have also been found as well as loss of taste sensation. In addition, there may be marked dryness of the mouth, nose and eyes. While recovery from the milder neurological disabilities usually occurs; in more severe cases this is rarely complete, indicating that neuron destruction has probably occurred in these. Two negative findings are also of importance. After TCE

Address for reprint requests: Professor J B Cavanagh, The Toxicology Unit, MRC Laboratories, Carshalton, Surrey SM5 4EF, UK.

Received 2 August 1988 and in revised form 16 October 1988. Accepted 21 October 1988 exposure symptoms and signs never begin in any but the Vth sensory nerve area, and moreover, peripheral limb nerves have never definitely been implicated. It is immaterial, moreover, whether the trichloroethylene is given by mouth or by inhalation so that a direct action of the chemical upon nerve endings during anaesthesia can be excluded. Because of these curious clinical circumstances, and their frequent association with crops of orofacial herpes simplex infection, one of us (JBC) has earlier suggested ${ }^{12}$ that these observations might be interpreted to mean that the pathological changes, rather than being direct toxic effects on the relevant cells, may be due to reactivation of herpes virus that is latent in most of us. The present survey sets out the argument that is the basis of this hypothesis.

\section{The clinical evidence}

Trichloroethylene has long been used as a valuable degreasing agent in industrial metalwork. Plessner ${ }^{34}$ noted that heavily exposed workers might develop anaesthesia in the Vth cranial nerve area, and it later came to be used in the treatment of trigeminal neuralgia ("tic doloureux"). In a thorough analysis of reported cases Glaser ${ }^{5}$ found that after either oral dosing with capsules of TCE or more usually inhalation, $15 \%$ of treated cases gained complete relief from neuralgia, while as many as $51 \%$ reported partial success. These clinical results imply that the effects of the chemical upon trigeminal nerves were by no means 
Table To show the distribution of the cranial nerve changes in cases with cranial nerve neuropathy following exposure to trichloroethylene. Note that the Vth cranial nerve is constantly affected: the remaining cranial nerves are affected less regularly. The cases of Henschler et al ${ }^{20}$ were exposed mainly to dichloroacetylene. Note the numbers of cases showing herpes simplex skin lesion

\begin{tabular}{|c|c|c|c|c|c|c|c|c|c|c|}
\hline \multirow[b]{2}{*}{ Case } & \multicolumn{9}{|c|}{ Cranial nerve nuclei } & \multirow[b]{2}{*}{ Herpetic lesions } \\
\hline & $I I I$ & $I V$ & $\boldsymbol{V}$ & $V I$ & $V I I$ & $I X$ & $X$ & $X I$ & $X I I$ & \\
\hline $1 / 1$ & - & - & + & - & - & - & - & - & - & - \\
\hline $1 / 2$ & - & - & + & - & + & - & - & - & - & $t^{*}$ \\
\hline $2 / 1$ & - & - & + & - & + & - & - & - & - & - \\
\hline $3 / 1$ & - & - & + & + & - & + & + & - & - & - \\
\hline $3 / 2$ & + & - & + & - & - & - & - & - & - & - \\
\hline $4 / 1$ & - & - & + & - & - & - & - & - & - & - \\
\hline $4 / 2$ & - & - & + & - & - & - & + & - & - & + \\
\hline $4 / 3$ & - & - & + & - & - & - & - & - & - & + \\
\hline $4 / 4$ & + & - & + & - & + & - & + & - & - & + \\
\hline $4 / 5$ & + & - & + & - & - & - & + & - & + & + \\
\hline $4 / 6$ & - & - & + & - & - & - & - & - & - & - \\
\hline $4 / 7$ & - & - & + & - & + & - & - & - & - & - \\
\hline $4 / 8$ & + & - & + & - & + & - & + & - & + & - died \\
\hline $4 / 9$ & - & - & + & - & + & - & - & - & - & + \\
\hline $4 / 12$ & - & - & + & - & + & - & - & - & - & + \\
\hline $4 / 13$ & - & - & + & - & + & - & - & - & - & + \\
\hline $5 / 1$ & - & - & + & - & - & - & - & - & - & - \\
\hline $5 / 2$ & - & - & + & - & - & - & - & - & - & + \\
\hline $5 / 3$ & + & - & + & + & + & + & + & - & + & - \\
\hline $5 / 4$ & + & - & + & + & + & + & + & - & + & -+ died \\
\hline $6 / 1$ & + & - & + & + & - & - & - & - & - & - \\
\hline $6 / 2$ & + & - & + & + & - & - & - & - & - & - \\
\hline $7 / 1$ & \pm & - & + & \pm & + & - & - & - & - & $-t$ \\
\hline $8 / 1$ & - & - & + & $\bar{t}$ & + & - & + & + & + & - \\
\hline
\end{tabular}

*Corneal herpes on 11 th day. + Transient visual field constriction.

Sources of case material.

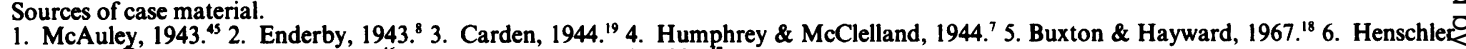
et al, $1970 .{ }^{20} 7$. Feldman et al, $19700^{46} 8$. Lawrence \& Partyck, 1981.

fortuitous. Significantly both Oljenick ${ }^{6}$ and Glaser $^{5}$ noted that only trigeminal neuralgia responded in this way, not neuralgia in any other cranial nerve.

When in later years trichloroethylene replaced chloroform as a general anaesthetic, a further batch of cases were reported in the literature but now an association with herpes simplex became apparent. In the course of a study of 13 such cases Humphrey and McClelland $^{7}$ seriously considered reactivation of herpes simplex virus infection as a possible mechanism of the neuropathy, since eight of their cases had shown typical herpetic orofacial lesions during the course of the illness. They also demonstrated neutralising antibodies to two strains of herpes virus in the serum of all cases, but with the methods then available they were unable to prove their case; nor were they able to transmit the infection by inoculation of brain tissue into mice, rabbits or to a rhesus monkey. None the less, this seemed a reasonable hypothesis.

Herpetic cold sores have only been reported in two of the remaining 13 published cases (table: cases $1 / 2$ and $7 / 1$ ). Whether this small additional number was due to such lesions being overlooked, and this is quite possible since in one reported case ${ }^{8}$ a small herpetic lesion was found on the cornea only on the 11th day of the illness, or whether their presence went unreportec because such apparently trivial lesions might not haveseemed relevant to the sometimes severe and debilitating neurological illness, is unknown. Orofacial herpes was also noted, but without the incidence being given, in the outbreaks of intoxication in space research studies and submariner cases reported by Saunders ${ }^{9}$ (and explained briefly later), so that the frequent occurrence found by Humphrey and McClelland seems unlikely to have been fortuitous.

The toxic condition continues to excite interest, however, because of the unusual distribution of the neurological changes, the unknown pathogenesis and the lack of success of any animal studies to reproduce these effects, ${ }^{10-17}$ either with trichloroethylene or with its breakdown product dichloroacetylene. Moreover, if this suggestion is true then the action of this chemical might help to throw light on the mechanism of activation of latency in herpes simplex virus infection. It also raises anew the question whether the CNS as well as trigeminal ganglia might be the nidus of the latent virus.

The morphological evidence

There have only been three post mortem studies in 
Man of trichloroethylene cranial neuropathy. Two cases in the series reported by Humphrey and McClelland ${ }^{7}$ died on days 2 and 16 respectively of their illness (cases $4 / 8$ and $4 / 11$ of the table), but only nonspecific changes with some small microglial clusters in the brain stem were reported by Dr W Pagel who did the necropsies; we do not known how extensive the neuropathological study was since an unspecified amount of brain material was taken for inoculation into animals in a search for a transmissible agent. The third post mortem study was fully reported by one of us $^{18}$ (case $5 / 4$, table). This man died from respiratory complications late in his illness (51 days) having experienced severe cranial nerve neuropathy. Morphologically, extensive destruction of axons in the tracts and nerve roots of the Vth cranial nerves was found, though the semilunar (Gasserian) ganglia were unfortunately not taken for study. The principal sensory Vth nucleus and the nucleus of the spinal tract showed extensive neuronal loss, while the motor Vth nuclei were less severely damaged, the neurons remaining being either normal or much vacuolated. Shrunken and degenerate neurons were evident in the VIth and VIIth nuclei, though many normal cells remained. The lateral and superior vestibular nuclei also showed degenerating neurons, and these were also visible in the nucleus giganto-cellularis and in the superior olivary nuclei. Neurons were lost from the reticular formation, the vagal and hypoglossal nuclei and from the solitary nucleus and its tract. Rostral to the Vth nucleus, the IIIrd nerve nucleus showed a few degenerating neurons, and these were also seen in the red nuclei, the substantia nigra, the posterior hypothalamus and in the mammillary bodies. The globus pallidus was similarly affected. In all these areas in which local spread of the pathological changes were seen there was concomitant astroglial hyperplasia and microglia were increased in numbers, though there was little or no inflammatory activity around vessels or elsewhere in the lesions. There was a similar paucity of inflammatory cells noted in the other two post mortem cases noted earlier.

To test the possibility that herpes simplex virus might be present in the tissue blocks from this case these were stained for herpes virus antigen using immunocytochemical methods and antibody supplied by Dakopatts (Buxton, unpublished data). No positive staining was found in any of these brain regions, but this negative finding is hardly surprising both because of the late stage of this patient's illness ( 51 days), and because detection by this method of herpesvirus antigen in tissues is insensitive and sometimes difficult even in a florid encephalitis.

\section{Possible pathogenetic mechanisms}

In summary, therefore, the clinical and pathological data strongly suggest that after severe exposure to trichloroethylene (and to dichloroacetylene, its breakdown product) something happens within the brain stem that begins in the sensory trigeminal area and spreads both rostrally and caudally leading to destruction of nerve cells in various centres that are topographically near one another, though not necessarily with any close functional connection. It is difficult to propose a purely toxicological explanation for such a regular sequence of effects in defined cranial nerves. All known neurotoxic chemicals are selective to particular neuronal structures or centres because these have some feature in common, such as axon length and size, energy consumption rates, specific transmitter metabolism and so forth, that allows a rational explanation to be proposed for the selective damage observed. In trichloroethylene intoxication selectivity from the outset is strictly to the trigeminal nerve area. Once this initial stage has occurred, however, subsequent damage that appears to be by local spread within the brain stem. No metabolic mechanism is known that is capable of regularly inducing this type of process, although such a possibility must first be examined since this is the current conventional explanation.

\section{Role of possible chemical toxicity}

Whether trichloroethylene, or its degradation product dichloroacetylene (fig), is in fact responsible for initiating these neurological events is still unanswered, though the latter appears to be the more likely agent. Earlier authors ${ }^{719}$ strongly suspected that the toxic syndrome was due to degradation of trichloroethylene to dichloroacetylene during its passage over soda lime in the currently employed anaesthetic apparatus (Boyle's), assisted by heat generated by the interaction. Humphrey and McClelland ${ }^{7}$ indeed, exposed two rabbits to anaesthetic mixtures containing $0.5 \%$ or $1.0 \%$ dichloroacetylene intermittently over a five day period, and found in the killed animals inflammatory changes in their brains. They did not, however, pursue the matter further and the significance of their findings is uncertain. The possible role of dichloroacetylene as the proximate toxic agent is strengthened by the report of two cases (cases $6 / 1$ and 6/2, table) of "polyneuritis cranialis" recorded by Henschler et al ${ }^{20}$ and Broser $e t$ $a l^{21}$ from exposure to a mixture of mono- and dichloroacetylene (vinylidine chloride), probably also contaminated by trichloroethylene. They showed the same signs and symptoms as those intoxicated with "Trilene", with early sensory Vth nerve involvement, later spreading to other cranial nerves, and extending even as far as 2 nd and 3rd cervical spinal levels. In an attempt to affect rabbits, Reichert et al ${ }^{22}$ exposed them to dichloroacetylene and reported disturbances to the corneal reflexes and other apparent sensory changes, 


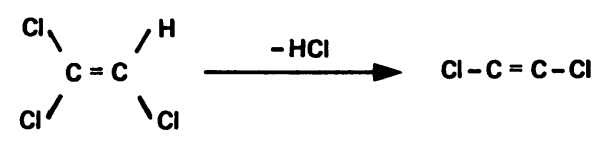

Trichloroethylene

Dichloroacetylene

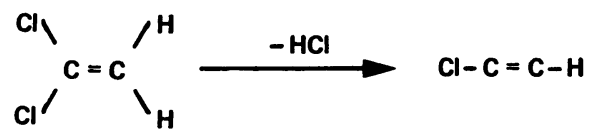

Dichloroethylene

(Vinylidene chloride)
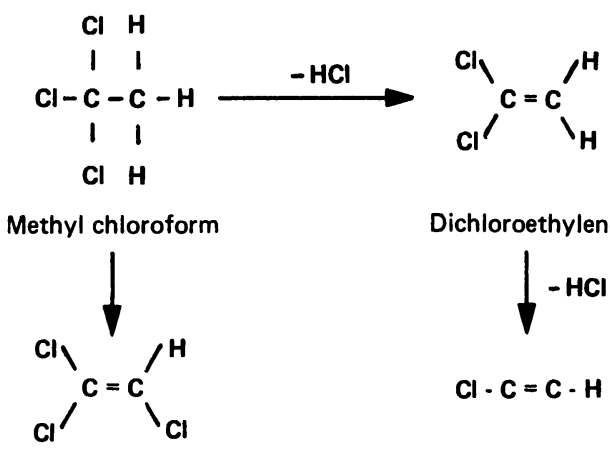

Dichloroethylene

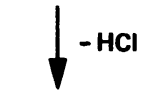

$\mathrm{Cl} \cdot \mathrm{C}=\mathrm{C} \cdot \mathrm{H}$

Trichloroethylene

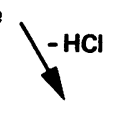

Monochloroacetylene

$\mathrm{Cl}-\mathrm{C}=\mathrm{C} \cdot \mathrm{Cl}$

Dichloroacetylene

Fig Chemical transformations of trichloroethylene.

but the tissue changes noted morphologically were after immersion fixation so their significance is difficult to assess, especially because of the almost universal presence of Encephalitozöon cuniculi in rabbits brains, a point not commented upon by the authors.

Further support for the probable importance of dichloroacetylene comes from two remarkable events chronicled by Saunders. ${ }^{9}$ In one episode volunteers in a mock-up of a space capsule and in the other seamen in a submarine both became affected by a fault in the air purification systcm in each case so that dichloroacetylene was released into the ambient atmosphere. The subjects developed symptoms similar to those after TCE anaesthesia, including Vth nerve sensory disturbances and the occurrence of herpes simplex orofacial cold sores. Unfortunately the number of individuals showing each of these clinical features was not stated. In the first outbreak they found that dichloroacetylene resulted from catalytic degradation of trichloroethylene in the atmosphere which had been used in preliminary cleaning of the capsule, while in the second dichloroacetylene was derived from methylchloroform used in adhesives in the heat insulators. These episodes thus tend to support the essential role of dichloroacetylene as the initiator in this sequence of pathological events, but its role in the nerve cell from that moment onwards is unknown.

\section{The role of possible virus reactivation}

As is now well established, herpes simplex virus infection of the nervous system may assume at least two forms. The primary, usually oral, infection to which most of us succumb in early life is a minor locally destructive process of acute inflammatory type. The virus in the primary infection finds its way from the epithelial surface along neural pathways to sensory ganglia, usually trigeminal, and probably also to the brain stem. Once neutralising antibodies appear in the blood the virus can no longer be found in ganglia or elsewhere, but by various means it can be shown that latent virus persists and can be reactivated in response to several types of stimulus. In the latent phase the virus undergoes periods of activity in response to external stimuli, acting directly or indirectly upon neurons in which the virus resides. Thus, after cutting the proximal root of the trigeminal ganglion for the treatment of trigeminal neuralgia, up to $93.6 \%$ of subjects were reported by Carton ${ }^{23}$ to show herpes simplex skin lesions. U.V. light, and X-irradiation, as well as more general stimuli in which the mechanism is unclear, such as a febrile illness, menstruation, etc., may initiate a local recurrence in susceptible individuals. It should be noted, however, and this is important for the present hypothesis, that local brain stem disease is not generally recognised as being associated with recrudescence of orofacial herpes. Furthermore, anaesthetic agents other than "Trilene" have not been known to induce orofacial herpes. Experimentally in the mouse, cellophane stripping of the ear skin, local application of $\mathrm{CO}_{2}$ snow, xylene or dimethyl sulphoxide (DMSO) are all effective in activating skin lesions. ${ }^{24}$ It should be noted, as a point against this present hypothesis, that in none of these "experimental" conditions in Man or in experimental animals, is there morphological or other evidence of virus activation in the brain stem pari passu with activation in the skin.

This phenomenon is intriguing and as yet unexplained despite an abundance of data that is sometimes apparently conflicting. ${ }^{24-26}$ There is little doubt that the virus remains in a latent state in ganglia after the acute primary infection has subsided and that it resides in neurons rather than in the satellite cells. But it is neither visible by ultrastructural or immuno- 
cytochemical methods nor is it transmissible by conventional methods unless the ganglion is first manipulated in some way. ${ }^{27}$ Thus, transplanting the ganglion to organ culture will allow the infection to materialise in 24-48 hours, ${ }^{28-32}$ a manoeuvre that in effect is equivalent to axotomy of all the contained neurons. Circulating IgG also seems to play an additional and significant role in this response.

The state of the viral genome in affected trigeminal neurons before reactivation is not known; virus certainly can be detected in mouse and rabbit ganglion neurons, ${ }^{33}$ although detectable HSV DNA equivalents are substantially fewer than during the acute infectious phase. ${ }^{34}$ The further finding by these last authors that viral mRNA sequences are scarecely if at all detectable during latency, suggests that the virus is in a truly nonreplicating form. Whether this apparent arrest of viral development is a specific property of the virus or whether as seems most likely it is the result of the metabolic state of the mature differentiated neuron in which it resides is undecided. A condition may exist in neurons that may be analogous to that found with this virus in macrophages, for here viral replication gradually ceases as the animals mature and eventually disappears altogether in the mature animals and the cells are no longer killed. ${ }^{35} 36$ In such circumstances viral regression is most probably related to the presence of arginase in adult macrophages, it being absent from immature animals. ${ }^{37}$ The highly specialised metabolic state of the differentiated neuron could conceivably be the prime reason for neuronal latency, and it is only on reversion of the neuron to a more generalised metabolic state, such as follows axotomy, that genetic products suitable for viral growth become available. Such a concept of the importance of the host cell in the latent state is implicit in the discussion of Hill. $^{24}$

\section{Activation of virus in brain stem neurons?}

While the presence of virus in trigeminal ganglia during latency is thus well established, whether it is resident in the human CNS during latency is less certain and on recrudescence of the herpetic skin lesions no signs relevant to the CNS have ever been reported. Moreover the reverse, namely recrudescence of orofacial herpes during the course of focal brain stem lesions, has not been reported. Knotts et al, ${ }^{33}$ Cook and Stevens $\mathrm{s}^{38}$ and Cabrera et al ${ }^{39}$ and others have been able to demonstrate virus in the brains of mice and rabbits during the latent phase, but always in substantially lesser amounts than in ganglia from the same animals; others have, however, been unsuccessful in demonstrating this. ${ }^{40}$ Its presence in human brain has been claimed by Sequeira et al, ${ }^{41}$ using in situ hybridisation techniques, but this was not confirmed by Efstathiou et al $^{42}$ who were able to demonstrate the presence of HSV specific DNA sequences in both CNS and PNS of mice in the latent phase, and in human trigeminal ganglia in cases with serum HSV antibodies, but not in brain stem material from the same subjects. The animal experiments, at least, encourage the conclusion that viral entry into the brain stem neurons may, in fact, be a regular event, but always in much smaller amounts than in ganglia. In Man this seems at present beyond the detection limit of current methods.

In this connection it is worth drawing attention to the mesencephalic nucleus of the $V$ th nerve as a possible nidus of latent virus. This is a cluster of primary sensory neurons which during development have, for some reason, not settled in peripheral ganglia but have come to lie in the upper brain stem close to the aqueduct and to the IIIrd and IVth cranial nerve nuclei. If the virus is resident in other sensory cells of the Vth nerve, this could be one site, though a very small one, in the CNS where virus might be detectable by suitably sensitive methods.

\section{Suggested mechanisms of neuronal damage in this "intoxication"}

Two possible mechanisms suggest themselves as to how HSV, or other types of latent virus might become involved in the lesion initiated by TCE. The first is that the chemical leads to viral activation in trigeminal ganglia and infectious particles then move along both peripherally and centrally directed axons to set up a reaction both in skin and in brain stem projection areas. The mesencephalic nuclei might be playing an important role here as initiation sites in the reactivation process. In the CNS the virus would pass from cell to cell destroying some neurons on the way, but cell damage and release of virus is unlikely to be sufficient to generate an overt inflammatory reaction. The fact that CNS lesions do not occur in association with banal orofacial infections would not be in favour of this first hypothesis.

The second possibility assumes that virus is already within brain stem neurons in latent form, despite present difficulties in identifying its whereabouts in human material. The differences noted above between mice and Man may only be quantitative in view of the large differences in the amount of virus received in each circumstance. On heavy exposure to TCE or dichloroacetylene these chemicals would readily enter the brain and activate virus latent within the brain stem, probably within neurons of the mesencephalic nuclei. The number of virus infected cells is likely to be few and virus would spread from cell to cell with little or no inflammatory reaction. The limited number of abnormal clinical signs in most cases of intoxication is in keeping with very limited spread from the initial site.

As to the initiation mechanism on the viral genome 
nothing much can be said but it could be critically important that this anaesthetic agent as well as dichloroacetylene both readily form epoxides in tissues, and in the case of trichloroethylene intramolecular rearrangements probably take place after the initial transformation that leads to the formation of chloral hydrate. ${ }^{43}$ Epoxides are nucleophilic and activation of lysogenic bacteria is a characteristic property of such compounds, ${ }^{44}$ but whether this is how viral activation might arise in this intoxication must remain for future studies.

Presently these are only deductions from known events, but perhaps the present hypothesis will lead to experimental studies to determine where the truth lies. If there is truth in these deductions, then a new, and hitherto unsuspected, role for toxic chemicals may have been displayed by this intoxication.

We are grateful to Dr Margaret Esiri for confirming our immunocytochemical findings and to the late $\mathrm{Dr}$ Peter Wildy, to Dr Hugh Field and to Professor P G E Kennedy for helpful discussion of the question of latent herpes virus and its possible activation in this intoxication. The first author wishes particularly to thank Dr A C Palmer, the Veterinary School, Cambridge, for his encouragement of this study.

\section{References}

1 Cavanagh JB. Mechanisms of organic solvent toxicity: morphological changes. In: Chronic Effects of Organic Solvents on the Central Nervous System and Diagnostic Criteria. W.H.O. and Nordic Council of Ministers Working Group. Copenhagen. 1985;110-35.

2 Cavanagh JB. Solvent Neurotoxicity. $\mathrm{Br} J$ Industr Med 1985;42:433-4.

3 Plessner $W$. Ueber Trigeminismuskrankung infolge von Trichlorathylenvergiftung. Neurol Zentralbl 1913;34:916-9.

4 Plessner $W$. Ueber Trigeminismuskrankung infolge von Trichlorathylenvergiftung. Berlin Klin Woch 1916;53:25-26.

5 Glaser MA. Treatment of trigeminal neuralgia with trichloroethylene. JAMA 1931;96:916-20.

6 Oljenick I. Trichloroethylene treatment of trigeminal neuralgia. JAMA 1928;91:1985-7.

7 Humphrey JHC, McClelland M. Cranial nerve palsies with herpes following general anaesthesia. $\mathrm{Br}$ Med J 1944;1:315-8.

8 Enderby GEH. The use and abuse of trichlorethylene. $\mathrm{Br} \mathrm{Med} \mathrm{J}$ 1944;ii:300-2.

9 Saunders RA. A new hazard in enclosed environmental atmospheres. Arch Environ Hlth 1967;14:380-4.

10 Adams EA, Spencer HC, Rowe VK, McCollister DD, Irish DD. Vapor toxicity of trichloroethylene determined by experiments on laboratory animals. Arch Industr Hyg Occupat Med 1951;4:469-81.

11 Rowe VK, McCollister DD, Spencer HC, Adams EM, Irish DD. Vapor toxicity of tetrachloroethylene for laboratory animals and human subjects. Arch Industr Hyg Occupat Med 1952;5:566-79.

12 Baker AG. The nervous system in trichloroethylene intoxication: an experimental study. I Neuropathol Exp Neurol 1958;17: 649-55.

13 Defalque RJ. Pharmacology and toxicology of trichloroethylene.
Clin Pharmacol Therap 1961;2:665-8.

14 Smith GF. Trichloroethylene: a review. $\mathrm{Br} J$ Industr Med 1966;23:249-62.

15 Siegel J, Jones RA, Coon RA, Lyon JP. Effects on experimental animals of acute repeated and continuous inhalation to dichloroacetylene mixtures. Toxicol Appl Pharmacol 1971;18:168-74.

16 Jackson MA, Lyon JP, Siegel J. Morphological changes in kidneys of rats exposed to dichloroacetylene-ether. Toxicol Appl Pharmacol 1971;18:175-84.

17 Henschler D, Romen W, Elsasser HM. Carcinogenicity study of trichloroethylene by long term inhalation in three animal species. Arch Toxicol 1980;43:237-48.

18 Buxton PH, Hayward M. Polyneuritis cranialis associated with industrial trichloroethylene poisoning. J Neurol Neurosurg Psychiatry 1967;30:511-8.

19 Carden S. Hazards in the use of closed-circuit technique for trilene anaesthesia. Br Med J 1944;1:319-20.

20 Henschler D, Broser F, Hopf HC. "Polyneuritis cranialis" durch vergiftung mit Chlorierte Acetylenen beim Umgang mit Vinylidenchlorid-copolymeren. Arch Toxicol 1970;26:62-75.

21 Broser F, Henschler D, Hopf HC. Chlorierte Acetylene als Ursache einer irreparablen Trigeminismusstorung bei zwie Patienten. Dtsch Ztschr Nervenh 1970;197:163-70.

22 Reichert D, Liebolt G, Henschler D. Neurotoxic effects of dichloroacetylene. Arch Toxicol 1976;37:23-38.

23 Carton CA. The effect of previous sensory loss on the appearance of herpes simplex following trigeminal sensory root section. J Neurosurg 1953;10:463-8.

24 Hill TJ. Herpes simplex virus latency. In: Roizman B, ed. The Herpesvirus, vol 3. 1985:175-240.

25 Hill TJ, Blyth WA. An alternative theory of herpes simplex recurrence and a possible role for prostaglandins. Lancet 1876;i:397-8.

26 Klein J. Pathogenesis of acute latent and recurrent herpes simplex infections. Arch Virol 1982;72:143-68.

27 Goodpasture EW. Herpetic infections with special reference to involvement of the nervous system. Medicine (Baltimore) 1929;8:223-43.

28 Stevens JG, Cook ML. Herpes simplex virus in spinal ganglia of mice. Science 1971;173:843-5.

29 Stevens JG, Cook ML. Maintenance of latent herpetic infection an apparant role for antiviral IgG. $J$ Immunology 1974;113:1685-93.

30 Stevens JG, Nesburn AB, Cook ML. Latent herpes simplex virus from trigeminal ganglia of rabbits with recurrent eye infections. Nature 1972;235:216-8.

31 McClennan JL, Darby G. Herpes simplex virus latency: cellular location of virus in dorsal root ganglia and the fate of the infected cell following virus activation. J Gen Virol 1980;51: 233-43.

32 Pazin GJ, Ho M, Janetta PJ. Reactivation of herpes simplex virus after decompression of the trigeminal nerve root. $J$ Infect Dis 1978;138:405-9.

33 Knotts FB, Cook ML, Stevens JG. Latent virus in the central nervous system of rabbits and mice. J Exp Med 1973;138:740-4.

34 Puga A, Rosenthal JD, Openshaw H, Notkins AL. Herpes simplex virus DNA and mRNA sequences in acutely and chronically infected trigeminal ganglia of mice. Virology 1978;89:102-11

35 Johnson RT. The pathogenesis of herpes virus encephalitis. II a cellular basis for the development of resistance with age. $J \operatorname{Exp}$ Med 1964;120:359-74.

36 Stevens JG, Cook ML. Restriction of herpes simplex virus by macrophages: an analysis of cell virus interaction. J Exp Med 1971;133:19-38.

37 Wildy P, Gell PGH, Rhodes J, Newton A. Inhibition of herpes simplex virus multiplication by activated macrophages: a role for arginase? Infect Immun 1982;37:40-45.

38 Cook ML, Stevens JG. Latent herpetic infection following experimental viraemia. J Gen Virol 1976;31:75-80. 
39 Cabrera CV, Wohlenberg C, Openshaw H, Roy Mendez M, Puga A, Notkins AL. Herpes simplex viruses-DNA sequences in the CNS in latently infected mice. Nature 1980;288:288-90.

40 Hill TJ, Blyth WA, Harbour DA, Berris EL, Tullo AB. Latency and other consequences of infection of the nervous system with herpes simplex virus. Prog Brain Res 1983;59:173-4.

41 Sequeira LW, Jennings LC, Carrasco LH, Currey A, Lord NIA, Sutton RNP. Detection of Herpes virus genome in brain tissue. Lancet 1979;ii:609-12.

42 Efstathiou S, Minson AC, Field HJ, Anderson JR, Wildy P. Detection of herpes simplex virus-specific DNA sequences in latently infected mice and humans. J Virol 1986;57:446-54

43 Henschler D. Metabolism and mutagenicity of halogenated olefins-a comparison of structure and activity. Environm Hlth Perspect 1977;21:61-64.

44 Reslova S. The induction of lysogenic strains of Escherichia coli by cis-dichloro-diammineplatinum.(II). Chem Biol Interact 1971/ 1972;4:66-70.

$45 \mathrm{McAuley} \mathrm{J}$. Trichlorethylene and trigeminal anaesthesia. $\mathrm{Br} \mathrm{Med} \mathrm{J}$ 1943;ii:713-4.

46 Feldman RG, Meyer RM, Taub A. Evidence for peripheral neurotoxic effect of trichloroethylene. Neurology 1970;20: 599-606.

47 Lawrence WH, Partyk EK. Chronic dysphagia and trigeminal anesthesia after trichloroethylene exposure. Ann Int Med 1981;95:710.

\section{The History of Neurology}

\section{Some British contributions to the history of multiple sclerosis}

The white matter plaques which characterise multiple sclerosis were described by Cruveilhier (1791-1874) ${ }^{1}$ the first professor of Pathological Anatomy in Paris, and by Sir Robert Carswell (1793-1857) ${ }^{2}$ whose training started in Glasgow. Carswell, described by Spillane as an "artist-pathologist" was the first Professor of Pathological Anatomy at University College (1828) and later personal physician to the King of the Belgians. His celebrated atlas describes: " 'A peculiar diseased state of the chord and pons Varolii, accompanied by atrophy of the discoloured portions'. Multiple sclerosis: 'yellowish brown' lesions in pons; hard, semitransparent, atrophied 'patches' in spinal chord; 'softening of a portion of the chord'."

Early clinical descriptions were provided by Frerichs and Rindfleisch. But the illness was not recognised until the writings of Vulpian and Charcot ${ }^{3}$ in France, and somewhat belatedly in Britain by Moxon ${ }^{4}$ :

"The recognition of this disease by English physicians will appear singularly slow... Although the two cases under my own care of which I shall give the post-mortem appearances are, as far as I know the only ones in which the diagnosis has been made sure by inspection after death, on this side of the channel ...

"The diagnostic characters of insular sclerosis are-

1. A peculiar trembling of the head and limbs during movements, ceasing when the parts are supported.

2. Paralytic weakness of the extremities without numbness.

3. Rigidity or contractions of the lower extremities.

4. Nystagmus (twitching of the eyeballs).

5. Little disturbance of power over the excretions.

6. Normal electro-irritability.

7. A peculiar affection of the speech, so that syllables are uttered with morbid distinctness of accent.

8. The intellect, and control of emotions ultimately somewhat impaired without morbid delusions or morbid moral aberration.

When these conditions exist in any patient, it is certain that patient has insular patches of grey change scattered throughout the brain and spinal cord."

Moxon differentiated the "trembling" from chorea and paralysis agitans, and from ataxia-presumably locomotor ataxia. He observed numbness, but lack of sensory techniques explains perhaps his second remark. 'Escape of urine' occurred late. Enfeeblement of mind included 'laughing incontinently and . . . weeping is equally out of just relation to its proper causes.' 'Hopefulness at one time and depression at another....'

Moxon stated "the disease belongs to the climax of life (25 to 45), its duration is very variable and may be prolonged over many years." He recognised early remissions "mild, scarcely recognisable for 5, 8, 10 or more (yrs), . . disabling characters of it coming out rather abruptly." He described the pathology of his two cases in detail emphasising: lesions in the white matter "scattered in a broadcast style, spherical rounded or oval patches of grey material, considerably harder than the rest of the brain substance." Astutely, he noted "a conspicuous vessel in the centre of a patch..."

\section{References}

1 Cruveilhier J. L'Anatomie pathologique du corps humain; descriptions avec figures lithographiées et coloriées; diverses alterations morbides dont le corps humain est susceptible. Vol 2; Liv 32, pl 2, pp 19-24; Liv 38, PI 5, pp 1-4. Paris: Bailliere, $1829-42$.

2 Carswell R. Illustrations of the Elementary Forms of Disease. PI IV. London: Longman, 1838.

3 Charcot M. Lectures on Diseases of the Nervous System. Vol i, p 214. Translated and edited by George Sigerson. London: The New Sydenham Society, 1881.

4 Moxon W. Eight cases of Insular Sclerosis of the brain and spinal chord. Guy's Hospital Reports 1875;20:437-80. 